\title{
Work-related carpal tunnel syndrome treatment: a cross-sectional study among 106 patients
}

\author{
M. Aouatef ${ }^{1}$, B. Asma ${ }^{2}$, H. Hajer ${ }^{1}$, A. Charfeddine', B. Lamia ${ }^{1}$, K. Taoufik ${ }^{1}$ \\ ${ }^{1}$ Department of Occupational Health \& Ergonomic, Faculty of Medicine of Monastir, University of Monastir, Tunisia; \\ ${ }^{2}$ Department of Physiology, University of Pharmacy of Monastir, University of Monastir, Tunisia
}

\begin{abstract}
SUMMARY
The objective is to assess the influence of sociodemographic, professional and clinical variables on the choice of treatment of work-related carpal tunnel syndrome (CTS).

An exhaustive and trans-sectional study was conducted over a period of eight years, from 1st January 2006 to 31 December 2013 in the Department of Occupational Medicine at University Hospital of Mahdia, Tunisia. The study population was represented by patients with work-related carpal tunnel syndrome. Data collection was based on a questionnaire sheet, describing social, occupational and medical characteristics of patients.

The study population was characterized by a large female dominance, representing $95.3 \%$ with an average age of $42 \pm 7.8$ years. Patients medically treated represented $38.7 \%$ and $61.3 \%$ had had surgical treatment. After binary logistic regression, surgical indication of CTS was significantly correlated to diabetes $(\mathrm{p}=0.017)$, other musculoskeletal disorders $(\mathrm{p}=0.02$ ), functional signs of CTS (acrocyanosis $\mathrm{p}=0.05$; muscle weakness $\mathrm{p}=0.015$; radiating pain $\mathrm{p}=0.01$; painful discomfort of the hand, the forearm or arm $\mathrm{p}=0.027$ ) and to the atrophy of thenar muscles $(\mathrm{p}=0.018)$.

According to this study, the choice of therapy for occupational CTS depends only on clinical data. More detailed studies will be needed to refine these results.
\end{abstract}

Key words: Carpal tunnel syndrome; Work related; Treatment.

\section{INTRODUCTION}

Carpal tunnel syndrome (CTS) remains

a public health problem, responsible for heavy socio-economic consequences $(1,2)$. In France, the number of workrelated CTS benefits increased around 10 times between 1991 and 2003 (2602 cases vs 24,000 cases), with a cost of more than 689 million euros (3). In the United States, the average cost of claims for compensation for work-related CTS is estimated at \$ 10,000 for one hand (4).

Surgical release of the CTS is a frequent treatment option. Such an approach weighs heavily on the budget of health and business insurance (4). Moreover, the review of scientific studies finds a disparity in guidelines of CTS treatment (5-7).

We carried out this work to determine the factors which can influence treatment of work-related CTS.

\section{PATIENTS AND METHODS}

This is a cross-sectional study carried out in the Department of Occupational Medicine of the University Hospital of Mahdia in Tunisia. The study was conducted from 1 January 2006 to December 2013. The study population was comprised of active employees, identified by consultation with the occupational health service and for whom the occupational origin of CTS had been ascertained, in conformity with Law No. 94-28 of 21 February 1994 concerning indemnity for occupational diseases according to Tunisian legislation (8).

During the study period, 106 patients with work-related CTS were identified and subdivided into two groups: a first group of medically treated patients (functional rehabilitation, local steroid injections and systemic treatment) and a second group of surgically treated patients. $\overline{\text { Corresponding author }}$ Mahfoudh Aouatef Department of Occupational Health \& Ergonomic,

Faculty of Medicine of Monastir University of Monastir, Tunisia E-mail: mahfoudhaouatef@gmail.com 
Collection of information was based on a fact sheet and completed by an investigating doctor. It included demographic characteristics (age, gender and symptoms, evolution...), medical information (duration of symptom evolution, functional signs, clinical data...) and occupational data (occupation, length of service, position occupied...)

To study psychosocial constraints at work, we used the Karasek questionnaire, designed by the American sociologist and psychologist Robert Karasek in 1979 (9, 10). This questionnaire consists of 26 questions: nine for psychological demands, nine for decisional latitude, and eight for social support.

The proposed answers are: Strongly disagree, Disagree, Agree, Strongly agree, which allows them to be scored from 1 to 4 and to calculate a score for each of the three sections. Job strain is defined as a situation where there is a score of psychological demands greater than 20 , decision latitude of less than 71, and a social support score of less than 24.5 (11).

\section{Statistical analysis}

The first step consisted of an overall description of the characteristics of the studied population in which frequencies were used for qualitative variables and means, while medians and standard deviations with determination of extent (extreme values) were reported for quantitative variables.

We used the Student's $t$ test and the ANOVA $f$ test in a univariate study comparing groups of medically and surgically treated patients. Variables with a degree of significance less than 0.2 are included in the multivariate analysis, which is based on multiple binary logistic regressions. The significant level was taken as $\mathrm{p}<0.05$.

\section{RESULTS}

The study population was characterized by a female predominance with a sex ratio of male to female of 0.05 . Those aged 30 to 49 years accounted $36.8 \%$. More than half the patients were married and had an average of three children. The distribution of employees by professional sector showed a predominance of the clothing sector $(74.5 \%)$ and the most common work stations were represented by machine operators $(54.7 \%)$ and housekeepers $(12.2 \%)$. The average length of service was $20.6 \pm 6.8$ years. The main biomechanical constraints reported were repetitive tasks using the wrist $(87.7 \%)$ and the toughness of the work $(40.5 \%)$. All employees were in a situation of job strain.

Functional complaints were bilateral in $65.2 \%$ of patients.

Tinel and Phalen signs were respectively present in $90.5 \%$ and $85.8 \%$ of cases. Electromyogram (EMG) was performed in all patients. Impairment was bilateral in $69.8 \%$ of cases. More than half the patients had moderate-stage of CTS with a frequency of $56.1 \%$ on the right side and $50.6 \%$ on the left side.

In this study, therapeutic choice of workrelated CTS was significantly correlated to marital status $(\mathrm{p}=0.05)$, association with other musculoskeletal disorders (tendonitis of the rotator cuff, epicondylitis, cervico-brachiale neuralgia, De Quervain disease $)(\mathrm{p}=0.02)$ and to diabetes $(p=0.04)$. In addition, we have noted that the type and the stage of impairment at the EMG results were not associated with the choice of the treatment of work-related CTS (Table I).

Among professional factors, position occupied and occupational status of employees had a significant impact on CTS therapeutic decisions $(\mathrm{p}=0.02, \mathrm{p}=0.04)$, which depended also on the affected $\operatorname{limb}(\mathrm{p}=0.05)$, acrocyanosis $(\mathrm{p}=0.04)$, irradiation of paresthesia in the upper limb $(p=0.01)$ and bilateral involvement of the median nerve at the EMG $(p=0.05)$ (Table II).

In our study, the indication for surgical treatment was significantly associated with the pre-existence of diabetes, other musculoskeletal disorders, and functional signs of the disease (acrocyanosis, muscular weakness, irradiation of paresthesia, painful discomfort in hand, forearm, or arm) and to atrophy of thenar muscles (Table III). 


\section{DISCUSSION}

In this study, $38.6 \%$ of patients had received a medical treatment and $61.4 \%$ surgical treatment. This procedure has become one of the most common treatment options of CTS. Tuppin et al., in a study conducted in France in 2008, reported that 127,269 patients have had a surgery treatment of CTS with an increase of $25.2 \%$ over 9 years and an annual increase of $2.8 \%$. There may be many reasons for this, including an increased prevalence of some comorbidities associated with CSC such as diabetes and obesity, work condition with particularly exposition to biomechanics risks (12).

Open surgical or endoscopic surgical techniques are no different in terms of clinical effectiveness and safety of use with a success rate of around $99 \%$ (13).

Table I - Influence of socio-demographic factors on Work-related CTS treatment in univariate analysis.

\begin{tabular}{|c|c|c|c|c|c|c|c|}
\hline & \multicolumn{2}{|c|}{ Medically treated group } & \multicolumn{2}{|c|}{ Surgically Treated group } & \multirow{2}{*}{$\mathbf{P}$} \\
\hline & & & Effective & $\%$ & Effective & $\%$ & \\
\hline \multirow{2}{*}{ Gender } & \multicolumn{2}{|l|}{ Female } & 38 & 35.8 & 63 & 59.4 & \multirow{2}{*}{0.37} \\
\hline & \multicolumn{2}{|l|}{ Male } & 3 & 2.8 & 2 & 1.8 & \\
\hline \multirow{4}{*}{ Age (years) } & \multicolumn{2}{|l|}{$<30$} & 1 & 0.9 & 2 & 1.8 & \multirow{4}{*}{0.49} \\
\hline & \multicolumn{2}{|l|}{$30-39$} & 12 & 11.3 & 27 & 25.4 & \\
\hline & \multicolumn{2}{|l|}{$40-49$} & 16 & 15 & 24 & 22.6 & \\
\hline & \multicolumn{2}{|l|}{$>50$} & 12 & 11.3 & 12 & 11.3 & \\
\hline \multirow{3}{*}{$\begin{array}{l}\text { Upper limb } \\
\text { dominant }\end{array}$} & \multicolumn{2}{|l|}{ Right } & 39 & 36.7 & 56 & 52.8 & \multirow{3}{*}{0.31} \\
\hline & \multicolumn{2}{|l|}{ Left } & 2 & 11.3 & 8 & 7.5 & \\
\hline & \multicolumn{2}{|l|}{ Ambidextrous } & 0 & & 1 & 0.9 & \\
\hline \multirow{4}{*}{ Civil status } & \multicolumn{2}{|l|}{ Single } & 5 & 4.7 & 11 & 10.3 & \multirow{4}{*}{0.05} \\
\hline & \multicolumn{2}{|l|}{ Married } & 33 & 31.1 & 42 & 39.6 & \\
\hline & \multicolumn{2}{|l|}{ Divorced } & 0 & & 9 & 8.4 & \\
\hline & \multicolumn{2}{|l|}{ Widowed } & 3 & 2.8 & 3 & 2.8 & \\
\hline \multicolumn{3}{|l|}{ Diabetes } & 10 & 9.4 & 1 & 0.9 & 0.04 \\
\hline \multicolumn{3}{|c|}{ High blood pressure } & 7 & 6.6 & 6 & 5.6 & 0.55 \\
\hline \multicolumn{3}{|c|}{ Hypothyroidism } & 5 & 4.7 & 2 & 1.8 & 0.70 \\
\hline \multicolumn{3}{|l|}{ Dyslipidimia } & 5 & 4.7 & 1 & 0.9 & 0.40 \\
\hline Wrist trauma & & & 1 & 0.9 & 1 & 0.9 & 0.33 \\
\hline Others musckel & al disorders & & 19 & 17.9 & 45 & 42.4 & 0.02 \\
\hline & & Beginner & 6 & 5.6 & 15 & 14.1 & \\
\hline & At the left hand & Moderate & 1 & 0.9 & 2 & 1.8 & 0.81 \\
\hline Type of EMG & & Severe & 20 & 18.8 & 35 & 33 & \\
\hline impairment & & Beginner & 9 & 8.4 & 19 & 17.9 & \\
\hline & $\begin{array}{l}\text { At the right } \\
\text { hand }\end{array}$ & Moderate & 1 & 0.9 & 3 & 2.8 & 0.70 \\
\hline & & Severe & 26 & 24.5 & 40 & 37.3 & \\
\hline & & Sensitive & 13 & 12.2 & 17 & 16 & \\
\hline & At the left hand & Motrice & 11 & 10.3 & 29 & 27.3 & 0.38 \\
\hline Stage of EMG & & Sensitivomotrice & 3 & 2.8 & 6 & 5.6 & \\
\hline Impairment & & Sensitive & 11 & 10.3 & 11 & 10.3 & \\
\hline & $\begin{array}{l}\text { at the right } \\
\text { hand }\end{array}$ & Motrice & 19 & 17.9 & 19 & 17.9 & 0.68 \\
\hline & & Sensitivomotrice & 6 & 5.6 & 6 & 5.6 & \\
\hline
\end{tabular}


Table II - Influence of professional factors on Work-related CTS treatment in univariate analysis.

\begin{tabular}{|c|c|c|c|c|c|c|}
\hline & & \multicolumn{2}{|c|}{ Medically treated group } & \multicolumn{2}{|c|}{ Surgically treated group } & \multirow{2}{*}{$p$} \\
\hline & & Effective & $\%$ & Effective & $\%$ & \\
\hline \multirow{2}{*}{ Activity sector } & Textile production & 29 & 27.3 & 50 & 47.1 & \multirow{2}{*}{0.5} \\
\hline & Other sectors & 12 & 11.3 & 15 & 14.1 & \\
\hline \multirow{2}{*}{ Post occupied } & Operator on stamping & 19 & 17.9 & 39 & 36.7 & \multirow{2}{*}{0.02} \\
\hline & others & 22 & 20.7 & 26 & 24.5 & \\
\hline \multirow{4}{*}{ Professional seniority (years) } & $5-9$ & 3 & 2.8 & 4 & 3.7 & \multirow{4}{*}{0.76} \\
\hline & $10-20$ & 11 & 10.3 & 23 & 21.6 & \\
\hline & $20-29$ & 24 & 22.6 & 32 & 30.1 & \\
\hline & $30-39$ & 3 & 2.8 & 6 & 5.6 & \\
\hline \multirow{3}{*}{$\begin{array}{l}\text { Professional seniority } \\
\text { in the workplace (years) }\end{array}$} & $<5$ & 5 & 4.7 & 5 & 4.7 & \multirow{3}{*}{0.30} \\
\hline & $6-20$ & 19 & 17.9 & 40 & 37.7 & \\
\hline & $>20$ & 17 & 16 & 20 & 18.8 & \\
\hline \multirow{3}{*}{ Professional situation } & Holder & 34 & 32 & 59 & 55.9 & \multirow{3}{*}{0.04} \\
\hline & Contractuel & 4 & 3.7 & 6 & 5.6 & \\
\hline & Others & 3 & 2.8 & 0 & 0 & \\
\hline
\end{tabular}

Table III - Binary logistic regression of factors influencing work-related CTS treatment.

\begin{tabular}{|l|c|c|c|}
\hline & $\mathbf{p}$ & Beta & IC \\
\hline Diabetes & 0.017 & 18 & {$[1.69-19.44]$} \\
\hline Others musckeletal disorders & 0.002 & 5.66 & {$[1.93-16.5]$} \\
\hline Acrocyanosis & 0.05 & 0.15 & {$[0.02-1]$} \\
\hline Muscular weakness & 0.015 & 6.03 & {$[1.41-25.64]$} \\
\hline Irradiation of paresthesia & 0.01 & 0.27 & {$[0.10-0.73]$} \\
\hline Painful discomfort of the hand/the forearm or arm & 0.027 & 4.32 & {$[1.17-15.85]$} \\
\hline Atrophy of thenarian muscles & 0.018 & 34.72 & {$[1.85-49.61]$} \\
\hline
\end{tabular}

Samson noted that the effectiveness of conservative treatments is usually temporary. Medium to long-term recurrence would affect $75-90 \%$ of patients (14).

The Gerritsen study, conducted among 176 patients with idiopathic CTS, comparing conservative treatment results, using splinting, and the surgical treatment of CTS, has shown that surgery was more effective. Indeed, satisfactory results after 3 months of treatment were observed in $80 \%$ of patients and in 54\% of the second group. Referring to the same study, the long-term results of surgical treatment were more satisfactory compared to those treated with a splint, with a prevalence of $90 \%$ and $75 \%$ respectively (15).

In spite of the evolution in modalities of
CTS care, there is no universal consensus on the therapeutic management of this disease. Often, medical treatment is indicated in early forms without signs of clinical (objective disorder of sensitivity, weakness or amyotrophic of external muscles) or EMG severity (axonal loss). Also, secondary states (abnormal position of the wrist, untreated medical condition, and complication of pregnancy...) can benefit from a conservative treatment. For severe forms and those resistant to conservative treatment, surgical release of the median nerve would seem to be indicated (16-18).

Through the literature, guidelines have been published to simplify CTS therapeutic choices. In 2008, the American Academy of Orthopedic Surgeons published rec- 
ommendations for the indication of CTS surgical treatment:

Recommendation 1: Early surgery is indicated when there are clinical signs of denervation of the median nerve.

Recommendation 2: Surgery is indicated when the current treatment fails to resolve the symptoms within two to seven weeks (19).

The British Society of Hand Surgery has also issued recommendations regarding the treatment of CTS. Surgery is indicated when conservative treatment has failed and for severe CTS symptoms. It is also indicated for people who have CTS combined with diabetes, arthritis and cervical spondylarthrosis (20).

CTS surgery in Ireland is indicated for patients with severe symptoms and signs of neurological deficit, including constant paresthesia, numbness, pain, and muscular atrophy, weakness of the joints or changes in the EMG. It is also indicated for those whose symptoms are severe, acute and significantly interfere with daily work (21). In our study, factors influencing workrelated CTS treatment were significantly dependent on decreased muscle strength of the affected hand and associated with comorbidities, particularly diabetes and other musculoskeletal disorders of the upper limbs.

The type and stage of median nerve involvement at the EMG did not influence the type of treatment of employees with work-related CTS. Similar findings have been described by Laulan who concluded that the normality of EMG is not a contraindication to surgical treatment in typical CTS cases, provided the symptoms are specific and disabling (22).

Based on these findings, CTS treatment depends on the clinical and/or para-clinical history of patients. However, according to Rozmaryn, therapeutic choice for CTS must take into account the professional activity of patients (23).

\section{CONCLUSIONS}

According to our data, the choice of therapy for work-related CTS depends only on clinical data. A better understanding of factors influencing the severity of CTS may identify individuals who can benefit from conservative treatment. At the same time, individuals who are at risk of chronic CTS and/or who are more likely to receive surgical treatment can also be identified and treated appropriately.

This study has several known limitations, such as the relatively small sample size.

The descriptive nature of this study also was a limitation. Reliance on records kept by a variety of professionals over a period of several years caused limitations in the amount of information that was available. Also, professional constraints such as biomechanics and psychosocial factors were assessed subjectively. Furthermore, if this study could have been done in a prospective design, valuable information such as patient expectations and ergonomic factors could have been collected. More detailed studies will be needed to refine these results.

Conflit of interest: the authors declare no conflict of interest.

\section{REFERENCES}

1. Dias JJ, Burke FD, Wildin CJ, et al. Carpal tunnel syndrome and work. J Hand Surg. 2004; 29: 329-33.

2. Dias JJ, Bhowal B, Wildin CJ, Thompson JR. Carpal tunnel decompression. Is lengthening of the flexor retinaculum better than simple division? J Hand Surg. 2004; 29: 271-6.

3. Szabo RM. Carpal tunnel syndrome as a repetitive motion disorder. Clin Orthop Relat Res. 1998; 351: 78-89.

4. Chaise F, Bellemère $P$, Friol JP, et al. Interruption professionnelle et chirurgie des syndromes du canal carpien. Résultats d'une série prospective de 233 patients. Chir Main. 2001; 20: 117-21.

5. Maggard MA, Harness NG, Chang WT, et al. Indications for performing carpal tunnel surgery: clinical quality measures. Plast Reconstr Surg. 2010; 126: 169-79.

6. Keith MW, Masear V, Chung KC, et al. American Academy of Orthopaedic Surgeons clinical practice guideline on the treatment of carpal tunnel syndrome. J Bone Joint Surg Am. 2010; 92: 218-9.

7. National Institute for Health and Care Excellence. Carpal tunnel syndrome. NIHR, 2012. Available from: http://cks.nice.org.uk/carpal- 
tunnelsyndrome\#!scenario recommendation: 1 Accessed: 10 Apr 2014.

8. International Labour Organization. Loi n. 9428 du 21 février 1994 portant régime de réparation des préjudices résultant des accidents du travail et des maladies professionnelles. Journal officiel de la République tunisienne, 1994; 15: 308-318. Available from: http://www.ilo. org/dyn/natlex/natlex4.detail?p_lang=en\&p_ isn $=38574$

9. Karasek R. Job demands, job decision Latitude, and mental strain: Implications for job redesign. Admin Sci Q. 1979; 24: 285-308.

10. Zirwatul Aida R, Ibrahim R. Application of Karasek's Model on Job Satisfaction of Malaysian Workers. Int J Arts Commerce. 2013; 2: 149-62.

11. Karasek R, Brisson C, Kawakami N, et al. The Job Content Questionnaire (JCQ): an instrument for internationally comparative assessments of psychosocial job characteristics. J Occup Health Psychol. 1998; 3: 322.

12. Tuppin $\mathrm{P}$, Blotière PO, Weill $\mathrm{A}$, et al. Carpal tunnel syndrome surgery in France in 2008: patients' characteristics and management. Rev Neurol. 2011; 167: 905-15.

13. Service évaluation des technologies - Service évaluation économique. Chirurgie du syndrome du canal carpien idiopathique: étude comparative des techniques a ciel ouvert et des techniques endoscopiques. Paris: Agence Nationale d'Accréditation et d'Évaluation en Santé (ANAES); 2000. Available from: http:// www.unilim.fr/campusneurochirurgie/IMG/ HAS_chir_canal_carpien_etude_comp tech_ ouverte_et_endoscopique_HAS.pdf

14. Samson P. Le syndrome du canal carpien. Chir Main. 2004; 23: 165-77.

15. Gerritsen AA, de Vet HC, Scholten RJ, et al. Splinting vs surgery in the treatment of carpal tunnel syndrome: a randomized controlled trial. JAMA. 2002; 288: 1245-51.
16. De Santé, Haute Autorité. Chirurgie du syndrome du canal carpien: approche multidimensionnelle pour une décision pertinente. Note de recadrage. Paris: HAS; 2011. Available from: http://www.has-sante.fr/portail/upload/docs/application/pdf/2012-10/

17. Maggard MA, Harness NG, Chang WT, et al. Indications for performing carpal tunnel surgery: clinical quality measures. Plast Reconstr Surg. 2010; 126: 169-79.

18. Franklin GM, Friedman AS. Work-related carpal tunnel syndrome: diagnosis and treatment guideline. Phys Med Rehabil Clin N Am. 2015; 26: 523-37.

19. Keith MW, Masear V, Chung KC, et al. American Academy of Orthopaedic Surgeons clinical practice guideline on the treatment of carpal tunnel syndrome. J Bone Joint Surg Am. 2010; 92: 218-9.

20. Britsh Orthopaedic Association (BSSH); British Orthopaedic Association (BOA), Royal College of Surgeons of England (RCSEng). Commissioning guide: Treatment of painful tingling fingers; 2013. Available from: https:// www.rcseng.ac.uk/-/media/files/rcs/libraryand-publications/non-journal-publications/ treatment-of-painful-tingling-fingers-commissioning-guide.pdf

21. National Institute for Health and Care Excellence. Carpal tunnel syndrome. NIHR 2012. Available from: http://cks.nice.org.uk/carpaltunnelsyndrome\#!scenariorecommendation:1

22. Laulan J, Layas A, Kerjean Y. Membre supérieur et pathologie professionelle: Chirurgie du syndrome du canal carpien dans un contexte professionnel. Edition Masson; 2000; 145-51.

23. Rozmaryn LM, Dovelle S, Rothman ER, et al. Nerve and tendon gliding exercises and the conservative management of carpal tunnel syndrome. J Hand Ther. 1998; 11: 171-9. 